\title{
The Perceptions of Patients, their Parents and Healthcare Providers on the Transition of Young Adults with Type 1 Diabetes to Adult Services in the West of Ireland.
}

\author{
Ó Walsh', M Wynne², M O’ Donnell', M C O’Hara4, R Geoghegan³ \\ 1. Paediatric Department, University Hospital Galway, Newcastle Road, Galway, Ireland. \\ 2. School of Medicine, National University of Ireland Galway, University Road, Galway, Ireland. \\ 3. Academic Department of Medicine, National University of Ireland Galway, University Road, Galway, Ireland. \\ 4. Research and Development, HSE Strategic Planning and Transformation
}

\section{Abstract}

\section{$\underline{\text { Aim }}$}

This study aims to describe the perceptions of young adults', parents of young adults' and health care professionals' (HCPs) of the transition process for young adults with Type 1 Diabetes in the West of Ireland.

Methods

Thematic analysis of semi-structured interviews conducted with the three stakeholder groups was performed.

Results

Young adults hardly noticed the transition, with many of them seeing it as a physical move, whereas parents were more anxious and felt their involvement was still needed but not accommodated. Both groups perceived the young adults' ability to manage their diabetes as a facilitator, as well as the continuity of care provided by the diabetes nurse. Resource limitations and an inability of a young adult to selfmanage were identified as barriers to smooth transition by parents, whilst HCPs were experiencing problems with non-attendance and a lack of a psychology service.

\section{Conclusion}

This study highlights the importance of encouraging adolescents' autonomy in the years leading to transition. A key healthcare professional link between both services appears to facilitate smooth transition. Being flexible and supportive of both parents and adolescents including the provision of mental health services are other important considerations. 


\section{Introduction}

In adolescence and young adulthood there is a gradual shift in diabetes management from parental supervised care to patient self-management ${ }^{1}$. Traditionally, the move from the paediatric to adult service has been abrupt and poorly coordinated, resulting in poor glycemic control, loss to follow-up and poor health care outcomes ${ }^{2,3,4}$. Therefore, transition programmes are increasingly advocated to facilitate a smooth transition, with a shift from bureaucratic health-care structures to meeting the needs of the adolescent. The American Diabetes Association (ADA) produced guidelines on ensuring an effective transition process. These include expert, but not necessarily evidence-based recommendations on transition programme components, including structured patient education, self-management skills training, provision of written information on transition process, resource links provision, allocation of a transition coordinator, structured age appropriate screening and health promotion $^{1}$

A recently published systematic review suggests that these transition interventions may be effective in reducing diabetic ketoacidosis episodes and maintaining glycemic control post transition but concluded that further research is required to determine which programme types are most effective ${ }^{5}$. This study aims to describe the perceptions of young adults', parents of young adults' and HCPs of the transition process for young adults with Type 1 Diabetes in the West of Ireland.

\section{Methods}

In each of the 3 participating hospitals the transition process typically occurs the summer after the Leaving Certificate over 3 clinic visits; firstly, the Adult staff attend the Paediatric clinic, then the Paediatric staff attend the Adult clinic and finally the adolescent joins the Adult Diabetes Clinic. However, there are some variations between the hospitals; In the first hospital, where there are 6 12 transitions per year, the adolescents transition from a teen clinic to a young adult clinic that have a common Advanced Nurse Practitioner (ANP). In the second hospital, transition occurs in an ANPled young adult clinic, with 5-10 transitions per year. In the third hospital, transition involves only a change in consultant with 5-6 transitions per year.

Inclusion criteria included: (i) young adults with type 1 diabetes within 2 years of transitioning from paediatric to adult care services, (ii) parents of other young adults who have transitioned and (iii) the HCPs of these young adults. DIAMOND, a diabetes clinical information system used in the 3 hospitals, was used to identify the young adults who met the inclusion criteria. Interview participants were then purposively recruited to obtain a mix of young adults, parents of other young adults and HCPs in the 3 different hospitals. Ethical approval was obtained from the Research Ethics Committee, Galway University Hospitals, which covered all 3 hospitals within the group. Informed consent was obtained from all participants.

Qualitative research methodologies were employed. Purposive sampling was used to recruit participants from the 3 stakeholder groups in each of the three hospitals ${ }^{6}$. Semi-structured interviews on their experiences of the transition process were conducted. The interviews were informed by the dimensions of continuity in transition identified by Forbes et al. and were designed to gain an indepth understanding of their experiences of transition ${ }^{7}$. Interviews were audio-recorded and transcribed verbatim. To enhance the credibility of the data analysis, 2 investigators independently analyzed the transcripts and generated themes and codes, before collaborating to include only those that achieved consensus.

\section{Results}

A total of twenty participants were recruited representing a good mix of the different groups across the three sites $(n=20)$; six young adults (two from each of the different hospitals); seven parents of other young adults; and seven HCPs. The HCPs included one ANP and two doctors from the first 
hospital, one Diabetes Nurse Specialist (DNS) and doctor from the second and one DNS and doctor from the third.

\section{Perceptions of the transition Process:}

Young adults hardly noticed the transition as they had other priorities at the time, such as their friends and going to university. They knew it was going to happen and saw it as an inevitable step. Many saw it as a physical move and whilst it was not age dependant, most of them were 18 at the time (see upper panel of Table 1).

Parents' experiences of the process were quite different to the young adults. They felt their involvement was still needed but not accommodated within the system. They felt uncertain of their role during the transition, but the degree of their worry was dependent on their child's selfmanagement and not the service. Some were glad to see their children take more responsibility whilst others found being excluded from the adult service very difficult (see middle panel of Table 1).

HCPs felt that many of the ADA recommendations were being followed including preparation, referral, the provision of a transition coordinator and education. However, they were still experiencing problems with attendance in the young adult diabetes service, the approach to and timing of the transition process and the lack of a psychology service (see lower panel of Table 1)

Table 1. Quotes regarding experiences of the transition process

\begin{tabular}{|c|c|}
\hline & Experiences of the transition process \\
\hline Young Adults & $\begin{array}{l}\text { Hardly noticed it } \\
\text { "I can't even remember when it was but like, I don't remember them saying anything } \\
\text { special like..." } \\
\text { An inevitable step } \\
\text { "I think it was just that, you get old enough, go to the adult one...simple as that" } \\
\text { A physical move } \\
\text { "I was just moved from ... the teenage, or the younger clinic, to the adult one. That } \\
\text { was it really" } \\
\text { Self-management } \\
\text { "I suppose it's a very manageable part of my life.... I don't see any difference } \\
\text { between that and brushing my teeth" }\end{array}$ \\
\hline $\begin{array}{l}\text { Parents of } \\
\text { young adults }\end{array}$ & $\begin{array}{l}\text { Exclusion from adult services } \\
\text { "... they kind of don't encourage us to come" } \\
\text { "They just said "we're moving you over to the adult clinic"... Well it's kind of } \\
\text { Goodbye Mother!" } \\
\text { Young adult's self-management } \\
\text { "I was glad to see her taking responsibility for herself... rather than me hounding } \\
\text { her" } \\
\text { Timing of transition } \\
\text { "She says now she prefers the young adult unit because they talk to her like a } \\
\text { young adult" "she felt she was too old to be in Paeds... But then as a parent I } \\
\text { preferred it so... you can't keep everyone happy" }\end{array}$ \\
\hline $\begin{array}{l}\text { Healthcare } \\
\text { Professionals }\end{array}$ & $\begin{array}{l}\text { Preparation } \\
\text { "you let them know that they'll be moving on" } \\
\text { Referral } \\
\text { "discharge summary from paeds... tells you everything you need to know about } \\
\text { them" } \\
\text { Key person } \\
\text { "A is the paediatric and the adult nurse" } \\
\text { Education } \\
\text { "every consultation, alcohol is talked about with every single young adult... same } \\
\text { with smoking" } \\
\text { Attendance } \\
\text { "You have a } 50 \% \text { did not attend rate" } \\
\text { Approach to transition } \\
\text { "It's very tick-the-box" } \\
\text { Lack of psychology service } \\
\text { "You will know medically what is going on with them but from a psychological point } \\
\text { of view it is the joint paediatric-adult ANP that helps with that" } \\
\text { Timing } \\
\text { "lt's a very difficult time, and having a chronic disease, for some people, makes it } \\
\text { just really, really difficult" } \\
\text { "there's a lot of change in a young person's life - going to college, leaving } \\
\text { home...makes it even more difficult" }\end{array}$ \\
\hline
\end{tabular}


Adolescent's self-management and the continuity associated with the nurse being a common team member were the most important facilitators identified by both young adults and parents. Having contact with someone they knew from the paediatric service was hugely reassuring and they also found the encouraging and open consultation style, with regular follow up, extremely positive. Other facilitators included service flexibility and the provision of age banded clinics, both in the paediatrics and adult services (see Table 2).

The main perceived barrier for both young adults and their parents was when the young adult had a negative attitude towards their illness. For those who moved away from home to attend college they found getting home for clinics difficult at times. Other difficulties included the timing of the transition and the decreased frequency of appointments in the adult services compared to four a year in the paediatric service (see Table 2).

Some parents worried after being excluded from the adult services and felt that whilst HCPs provided education regarding alcohol and contraception on a one-to-one basis there was no formal education programme in place. They also identified resource limitations as barriers to transition (see Table 2).

Table 2. Quotes regarding perceived facilitators of and barriers to the transition process

\begin{tabular}{|c|c|c|}
\hline & Perceived facilitators & Perceived barriers \\
\hline Young Adults & $\begin{array}{l}\text { Self-management } \\
\text { "Once you're solely in charge of it, it } \\
\text { feels more manageable" } \\
\text { Continuity } \\
\text { "I haven't moved diabetes nurse and I } \\
\text { have quite a good relationship with her" } \\
\text { Consultation style } \\
\text { "Encouragement rather than criticism" } \\
\text { Flexibility } \\
\text { "Come in any day you have any } \\
\text { question or give me a call" } \\
\text { "Never felt like I was cast aside or didn't } \\
\text { have anyone to talk to" } \\
\text { Transition structure } \\
\text { "Moved on to a teenage service in the } \\
\text { pediatric unit... I found it very good" }\end{array}$ & $\begin{array}{l}\text { Attitude } \\
\text { "I know I should look after myself, l'm well } \\
\text { aware of the consequences, you } \\
\text { know. But l just really don't care, to tell } \\
\text { you the truth." } \\
\text { Other priorities } \\
\text { "When you're in college, you don't want to } \\
\text { take a day out to travel to Galway to go to } \\
\text { a clinic" } \\
\text { Timing } \\
\text { "Yeah, probably for me personally earlier } \\
\text { transition would be better... but that may } \\
\text { not be the same for everyone" }\end{array}$ \\
\hline $\begin{array}{l}\text { Parents of } \\
\text { young adults }\end{array}$ & $\begin{array}{l}\text { Young adult's self-management } \\
\text { "She basically takes complete } \\
\text { responsibility now" } \\
\text { Key person } \\
\text { "You always knew you could pick up the } \\
\text { phone and ring them... it's a nice kind of } \\
\text { a safety net to have" } \\
\text { Consultation style } \\
\text { "Very approachable; she seemed very } \\
\text { dedicated" } \\
\text { Follow up } \\
\text { "Good so to have a sort of similar } \\
\text { routine" }\end{array}$ & $\begin{array}{l}\text { Attitude } \\
\text { "He doesn't give one tuppenny damn } \\
\text { about diabetes; he wishes it wasn't there, } \\
\text { he's kind of angry about it at the moment" } \\
\text { Resource limitations } \\
\text { "Appointments only twice a year... not } \\
\text { enough... that's the health service and the } \\
\text { cutbacks" } \\
\text { Lack of structured education } \\
\text { "You can ring for advice, but there's no } \\
\text { actual program of education" } \\
\text { Exclusion from adult service } \\
\text { "/ don't know if they would contact me if } \\
\text { she was doing really badly." }\end{array}$ \\
\hline
\end{tabular}

\section{Discussion}

The results describe the perceptions of young adults', parents of young adults' HCPs of the transition process for youth with Type 1 Diabetes in the West of Ireland. It is essential that as HCPs we encourage adolescents to become more autonomous. An adolescents' ability to self-manage has a significant effect on their ability to maintain optimal glycaemic control and the perception of the transition process for both themselves and their parents.

Transition programmes can help them take on more responsibility for their diabetes, however their attendance is required for this to occur ${ }^{5}$. As previously described in the literature, clinic nonattendance was identified as a barrier to effective transition, with competing interests such as college 
taking priority over medical appointments ${ }^{8}$. Like many other studies, we found that a transition coordinator positively influences the transition experience. Ideally, the coordinator would be someone already known to the patient and family who can help them navigate this challenging period.

We also found that frequent team contact is extremely important. That could be in the form of more frequent appointments or telephone support and appointment reminders ${ }^{5}$. Improved communication with both the adolescent and their parents would also help address the issue of parental anxiety. Previous studies have demonstrated that high levels of parental anxiety can be potentially detrimental to the development of an adolescent's ability to develop self-management skills?. Therefore, we highlight the importance of working with and supporting both the parents and the adolescents during the transition process. Like Garvey et al., our HCPs identified poor access to mental health services as a significant barrier to effective transition ${ }^{8}$. HCPs depend on an ANP to perform the role of a psychologist, during a challenging time in an adolescent's life. The transition period is a time of great change in an adolescent's life, with many struggling to cope with the added pressure of a chronic health condition. Psychological support may help them with self-management and coping skills 5 .

Study limitations include the fact that this piece of qualitative research may not be generalizable beyond the West of Ireland, however our results add to the growing body of research on transition programmes in healthcare settings. Future research is needed to identify methods to overcome the barriers identified in this study. This is an important issue to explore as previously published evidence suggests that in the current configuration health care services are failing to meet the needs of adolescents/young adults with diabetes, resulting in compromised patient health, and unrealised potential $1,4,10$, increased hospitalisations and patient dissatisfaction.

These results highlight the importance of encouraging adolescents' autonomy and improving clinic attendance both of which can be facilitated by a transition coordinator. Being supportive of both parents and adolescents and including the provision of mental health services are other important considerations. Future research is needed to identify methods to encourage adolescents and young adults prioritize their diabetes self-management.

\section{Conflict of Interest}

The authors have read and understood the IMJ policy on declaration of interests and declare that they have no competing interests.

\section{Financial Support}

Miriam Wynne was awarded a Health Research Board (HRB) Summer Student Scholarship of $€ 2000$. This provided $€ 250$ per week for 8 weeks to pay for living and travel expenses during the project.

\section{Corresponding Author}

Dr. Órla Walsh, Adolescent Medicine Paediatrician, Assistant Professor University of Toronto, North York General Hospital, 4001 Leslie Street, Toronto, ON M2K1E1.

Email: orla.walsh@nygh.on.ca

\section{References}

1. Peters A, Laffel L, American Association Transitions Working Group. Diabetes Care for Emerging Adults: Recommendations for Transition from Paediatric to Adult Diabetes Care Systems. Diabetes Care. 2011 November; 34(11): 2477- 2485. PCMID: PMC31982

2. Lotstein DS, Seid M, Klingensmith G, Case D, Lawrence JM, Pihoker C, Dabelea D, Mayer-Davis EJ, Gilliam LK, Corathers S, Imperatore G, Dolan L, Anderson A, Bell RA, Waitzfelder B, SEARCH for Diabetes in Youth Study Group. Transition from Paediatric to Adult Care for Youth Diagnosed with Type 1 Diabetes in Adolescence. Paediatrics 2013;131:e1062-70. PMID: 23530167.

3. Veralto G, Muggeo M, Bonora E, Corbellini M, Bressan F, de Marco R. Attending the diabetes centres is associated with increased 5-year survival probability of diabetic patients. Diabetes Care 1996; 19: 211-213. 
4. Donnovan JL, Blake DR. Patient non-compliance: deviance or reasoned decision-making. Soc Sci Med 1992; 24: 507-513.

5. Schultz, A.T., Smaldone A. Components of Interventions That Improve Transitions to Adult Care for Adolescents with Type 1 Diabetes. J Adolesc Health. 2017, Volume 60, Issue 2, 133-146.

6. Smith T. Critical Appraisal of Quantitative and Qualitative Research Literature. Radiographer 6:6-10

7. Forbes A, While A, Ullman R, Lewis S, Lucia M, Griffiths P. A Multi- method review to identify components of practice which may promote continuity in the transition from child to adult care for young people with chronic illness or disability. National Co-ordinating Centre for NHS Service Delivery and Organisation R\&D. 2001.

8. Garvey KC, Telo GH, Needleman JS, Forbes P, Finkelstein JA, Laffel LM. Health care transition in young adults with type 1 diabetes: Perspectives of adult endocrinologists in the United States. Diabetes Care 2016; 39: 190-7

9. Blum RW, Garell D, Hodgman CH, Jorissen TW, Okinow NA, Orr DP, Slap GB. Transition from child-centered to adult health-care systems for adolescents with chronic conditions. A position paper of the Society for Adolescent Medicine. J Adolesc Health. 1993 Nov;14(7):570-6.

10. Allen D, Cohen D, Robling M, Hood K, Atwell C, Lane C, Gregory J, Lowes L, Channon S, Gillespie D, Groves S, Harvey J. The transition from paediatric to adult diabetes services: what works, for whom and in what circumstances? Final report. NIHR Service Delivery and Organisation programme. 2010. 